\title{
The coupled effect of light and temperature on dormancy release and germination of Pinus koraiensis seeds
}

\author{
Min Zhang ${ }^{1,2} \cdot$ Jiaojun Zhu ${ }^{1,2}$
}

Received: 7 April 2021 / Accepted: 6 July 2021 / Published online: 4 December 2021

(C) The Author(s) 2021

\begin{abstract}
Elucidating the regulatory mechanisms of environmental factors on seed dormancy and germination will provide guidance for tree regeneration. Toward understanding the coupled effect of light and temperature on dormancy release and germination of Pinus koraiensis seeds, we set up three light conditions (L200: $200 \mu \mathrm{mol} \mathrm{m} \mathrm{m}^{-2} \mathrm{~s}^{-1}$, L20: $20 \mu \mathrm{mol} \mathrm{m} \mathrm{m}^{-2} \mathrm{~s}^{-1}$, L0: $\left.0 \mu \mathrm{m}^{-2} \mathrm{~s}^{-1}\right)$ and four storage temperatures $\left[\mathrm{T}-5:-5{ }^{\circ} \mathrm{C}(50\right.$ days $), \mathrm{T} 5:-5^{\circ} \mathrm{C}(50$ days $)+5{ }^{\circ} \mathrm{C}$ (50 days $), \mathrm{T} 25:-5{ }^{\circ} \mathrm{C}(50$ days $)+5{ }^{\circ} \mathrm{C}(50$ days $)+25{ }^{\circ} \mathrm{C}$ (50 days), $\mathrm{T} 15:-5{ }^{\circ} \mathrm{C}(50$ days $)+5^{\circ} \mathrm{C}(50$ days $)+25^{\circ} \mathrm{C}$ (50 days) $+15^{\circ} \mathrm{C}$ (50 days)] using imbibed seeds, then quantified phytohormones gibberellic acid $\left(\mathrm{GA}_{3}\right)$ and abscisic acid (ABA) during the stratification. Germination percentage $\left(G_{\mathrm{P}}\right)$, mean germination time $\left(T_{\mathrm{M}}\right)$, and germination value $\left(G_{\mathrm{V}}\right)$ under $25 / 15^{\circ} \mathrm{C}$ temperature and the three light conditions were then determined. Phytohormone levels and germination performances were significantly affected by light and temperature. No consistent trend was found between the phytohormone levels and $G_{\mathrm{P}}$ caused by light levels. Under the three light conditions, ABA concentrations in the embryo and endosperm decreased as storage temperature shifted from T-5 to T25 and increased from T25 to T15;
\end{abstract}

Project funding: This work was supported by National Natural Science Foundation of China (No. 31830016 and 31800534 ).

The online version is available at http://www.springerlink.com.

Corresponding editor: Zhu Hong.

Jiaojun Zhu

jiaojunzhu@iae.ac.cn

1 Institute of Applied Ecology, Chinese Academy of Sciences, Shenyang 110016, People's Republic of China

2 Qingyuan Forest CERN, Chinese Academy of Sciences, Shenyang 110016, People's Republic of China
$\mathrm{GA}_{3}$ decreased in nearly all four storage temperatures. $G_{\mathrm{P}}$ reached $40-60 \%$ in T25 storage without light irradiance. In the three light conditions, $G_{\mathrm{P}}$ and $G_{\mathrm{V}}$ were higher at T5 and $\mathrm{T} 25$ than at $\mathrm{T}-5$ and $\mathrm{T} 15$; so T5 and T25 are considered as optimum storage temperatures for dormancy release and germination. At optimum temperatures, light (L200, L20) significantly increased the $G_{\mathrm{P}}$ and $G_{\mathrm{V}}$ compared with the dark (L0). At L200 and L20, significant negative correlations between $G_{\mathrm{V}}$ and the ABA concentrations and positive correlations between $G_{\mathrm{V}}$ and GA/ABA in the seed embryo were found. Temperature played a more important role in primary dormancy release and germination; light was unnecessary for primary dormancy release. Light facilitated seed germination at optimum temperatures. The dormancy release and germination of $P$. koraiensis seeds were controlled by a decrease in ABA concentrations or an increase in GA/ABA induced by temperature variations.

Keywords Seed germination - Gibberellic acid - Abscisic acid - Germination percentage $\cdot$ Cold stratification ·

Primary dormancy

\section{Introduction}

Seed dormancy and germination are distinct physiological processes in life cycle of plants (Bian et al. 2018). For many plant species, seeds are dormant at maturity and do not germinate until dormancy is released after exposure to optimal conditions (Chen et al. 2009; Baskin and Baskin 2014). Seed dormancy is a crucial, adaptive feature (Shu et al. 2016) to ensure higher survival of emergent seedlings under optimal conditions. Germination is a complex process that can be affected by biotic factors and abiotic factors. Some researchers have proposed that dormancy should be 
defined as a characteristic of the seed that determines the conditions required for germination rather than the absence of germination (Vleeshouwers et al. 1995; Thompson 2000; Fenner and Thompson 2005). When dormancy is considered in this way, any environmental cues that alter the conditions required for germination can be recognized as dormancy release factors (Finch-Savage and Leubner-Metzger 2006). Gibberellic acid (GA) and abscisic acid (ABA) are two prominent phytohormones that regulate dormancy release and seed germination processes (Vishal and Kumar 2018; Barreto et al. 2020; Song et al. 2020a; Yan and Chen 2020). ABA can induce or maintain seed dormancy, whereas GA stimulates seed germination (Finch-Savage and LeubnerMetzger 2006; Baskin and Baskin 2014). Storage at optimal environmental conditions for a specific period can be useful for releasing dormancy and promoting seed germination (Chen et al. 2009; Bian et al. 2018; Reum et al. 2018; Pipinis et al. 2020). For example, light irradiance is indispensable to activate the germination of some light-sensitive tree seeds such as Betula papyrifera (Brunvatne 1998), Pinus pinaster (Ruano et al. 2009), and Handroanthus impetiginosus (Carón et al. 2020). Taxus mairei seeds require wet stratification at alternating temperatures (warm stratification and then cold stratification) to break dormancy. The transition from dormancy to germination induced by suitable environmental factors results from variations in endogenous phytohormones in seeds (Liu et al. 2015). Most research has focused solely on one of the two processes, either seed dormancy or seed germination. In the present study, we focused on the two processes from dormancy to germination and clarified the respective roles of environmental cues (light, temperature) in these two processes.

Pinus koraiensis Siebold and Zucc. is a valuable, ancient tree species (Ma1997). It is one of the most important fiveleaved pine species in the northern hemisphere and distributed throughout Northeast Asia's mixed broadleaved Korean pine forests (MBKPF) (Hutchins et al. 1996), the regional climax vegetation type in mountainous areas of eastern China composed of $P$. koraiensis and broadleaved tree species. Due to a long history of overuse of forest resources, the MBKPF has undergone severe destruction. Emergent seedlings and saplings of $P$. koraiensis are rarely observed in the understory forest even during artificial regeneration. As an important dominant tree species in MBKPF, the unsuccessful regeneration of $P$. koraiensis greatly limits the recovery of MBKPF in broadleaved secondary forests. The deep dormancy of $P$. koraiensis seeds is one of the important factors contributing to the failure of natural regeneration for P. koraiensis population (Song and Zhu 2016; Song et al. 2018). Many of its seeds do not germinate until the third year after seed maturation due to the existence of primary and secondary dormancy (Song et al. 2018). To release the primary dormancy, cold stratification is usually applied to $P$. koraiensis seeds by mixing seeds into wet sand and burying the mixture the soil to overwinter from November toApril in temperate zones such as Northeast China. In secondary forests, we found that the emergence of $P$. koraiensis seedlings varied greatly in microhabitats with different light and temperature conditions. Thus, determining the optimal light and temperature conditions to release seed dormancy and germination should facilitate the natural regeneration of $P$. koraiensis. Song et al. (2016, 2018, 2020b) studied seed dormancy of $P$. koraiensis under different stratification temperatures and revealed that temperature significantly affected the dormancy release of $P$. koraiensis seeds. Zhang et al. (2015) indicated that $P$. koraiensis seed germination differed significantly under various light transmittances. However, whether the light condition also contributes to dormancy release of $P$. koraiensis seeds and whether light and temperature interact to release dormancy and promote germination of $P$. koraiensis seeds has not been determined. Answering these questions will inform methods to enhance regeneration of $P$. koraiensis. Therefore, here we sought to uncover any coupling of temperature and light conditions on processes from dormancy to seed germination of $P$. koraiensis seeds. We also compared germination attributes and GA and ABA dynamics in imbibed $P$. koraiensis seeds under different light and temperature conditions. Tests were designed to answer the following: (1) How do light and temperature conditions affect GA and ABA levels in imbibed seeds? (2) How does germination of the imbibed seeds respond to the light and temperature conditions? The results will provide a scientific basis for improving natural regeneration of $P$. koraiensis populations and further facilitate the recovery of MBKPFs in broadleaved secondary forests.

\section{Materials and methods}

\section{Seed source}

In late September 2018, P. koraiensis seeds were collected from at least 10 trees ( $>50$ years old) in the Qingyuan Forest CERN (Chinese Ecosystem Research Net) to guarantee genetic heterogeneity. Fresh seeds were dried at room temperature in the dark for about 60 days, and then stored at $-20{ }^{\circ} \mathrm{C}$ before use.

\section{Experimental design}

Approximately 10,200 P. koraiensis seeds were soaked in distilled water for 7 days for imbibition (the water was changed after 3 days). Floating seeds were removed to ensure viability of the seeds. The imbibed seeds were put on wet sand in a transparent plastic box, and then covered with wet sand to a $1 \mathrm{~cm}$ depth. All seeds were stored the 
same way ( 30 boxes total) and placed in growth chambers with 200,20 or $0 \mu \mathrm{mol} \mathrm{m}^{-2} \mathrm{~s}^{-1}$ (L200, L20, L0) of light (Fig. 1). For each light level, the temperature was set successively at $-5^{\circ} \mathrm{C}, 5^{\circ} \mathrm{C}, 25^{\circ} \mathrm{C}$, and $15^{\circ} \mathrm{C}$, with each temperature lasting for 50 days. Two boxes of seeds (ca. 800 seeds) from each light level were taken from the growth chamber every 50 days to test germination and quantify phytohormones. Rotten or moldy seeds were counted and removed. The storage temperature treatments for $P$. koraiensis seeds were designated as $\mathrm{T}-5\left(-5{ }^{\circ} \mathrm{C}\right.$ for 50 days), $\mathrm{T} 5$ $\left(-5{ }^{\circ} \mathrm{C}\right.$ for 50 days $+5{ }^{\circ} \mathrm{C}$ for 50 days), $\mathrm{T} 25\left(-5^{\circ} \mathrm{C}\right.$ for 50 days $+5{ }^{\circ} \mathrm{C}$ for 50 days $+25^{\circ} \mathrm{C}$ for 50 days $), \mathrm{T} 15\left(-5^{\circ} \mathrm{C}\right.$ for 50 days $+5{ }^{\circ} \mathrm{C}$ for 50 days $+25^{\circ} \mathrm{C}$ for 50 days $+15^{\circ} \mathrm{C}$ for 50 days). The period of seed stratification was designed to test the effect of environmental factors on the dormancy depth of $P$. koraiensis seeds.

After each stratification temperature treatment, 50 seeds with 5 replicates were cultivated at $25{ }^{\circ} \mathrm{C} / 15{ }^{\circ} \mathrm{C}$ temperature (represented as T-5 $\rightarrow 25 / 15$, T5 $\rightarrow 25 / 15$, T25 $\rightarrow 25 / 15$, $\mathrm{T} 15 \rightarrow 25 / 15$ respectively) at three light levels (L200, L20, L0) to test germination and thus the effect of light and temperature on germination. Germination was defined as the first needle sprout becoming visible (Argyris et al. 2008; Zhu et al. 2008). Every 80-100 seeds with three replicates were divided into testa, embryo and endosperm which were then ground separately in liquid nitrogen. The embryo and endosperm samples were wrapped in aluminimum foil and stored at $-20{ }^{\circ} \mathrm{C}$ before $\mathrm{GA}_{3}$ and $\mathrm{ABA}$ content analysis. The remaining seeds were used for analyzing the proteome in a study to be reported later.

$\mathrm{GA}_{3}$ and ABA in embryo and endosperm of $P$. koraiensis seeds were extracted by following the previous methods with some slight modifications (Kojima et al. 2009). The seed samples were ground into powder in liquid nitrogen. After that, $500 \mathrm{mg}$ fresh mass was determined for each sample and transferred to a $15 \mathrm{~mL}$ falcon tube. After the addition of $4 \mathrm{~mL}$ prechilled $\left(-30^{\circ} \mathrm{C}\right)$ extraction solvent (methanol:water:formic acid $=15: 4: 1$, the samples were vortexed for $45 \mathrm{~min}$. Kept the tubes overnight at $-30{ }^{\circ} \mathrm{C}$ to extract the hormones $\left(\mathrm{GA}_{3}\right.$ and $\mathrm{ABA}$ ). After centrifugation at 12,000 rpm for $15 \mathrm{~min}$, the supernatant was collected, and the residue was ultrasonically reextracted and centrifugated by following the above method. The extraction supernatants from both steps were combined. Samples and solutions were kept at $4{ }^{\circ} \mathrm{C}$ throughout the extractions. HLB and MCX columns were preactivated with $2 \mathrm{~mL}$ of methanol and $1 \mathrm{M}$ formic acid. Every $2 \mathrm{~mL}$ of the supernatants loaded onto an HLB column and successively washed with $1 \mathrm{~mL}$ extraction solvent. The eluates and washing solution were collected together and evaporated to $1 \mathrm{~mL}$ solution at $40^{\circ} \mathrm{C}$. The solution was passed through a MCX column eluting with $1 \mathrm{~mL}$ methanol and $1 \mathrm{~mL}$ of $1 \mathrm{M}$ formic acid. And the methanol fraction was concentrated and redissolved in $0.2 \mathrm{~mL}$ of methanol. Then the dissolved solutions were filtered

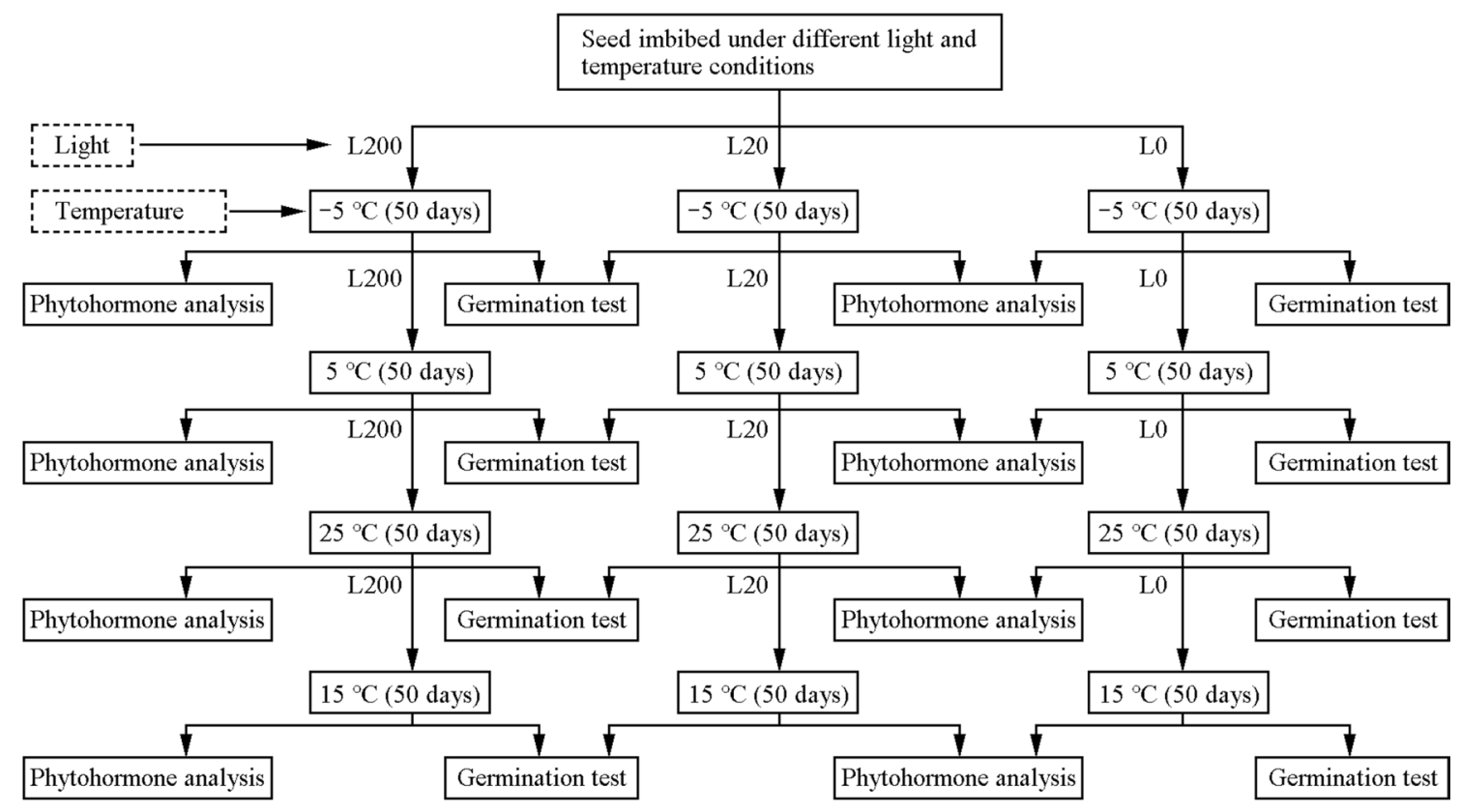

Fig. 1 Outline of experimental design to test the effect of light and temperature combinations on germination and phytohormone levels of Pinus koraiensis. L200 is $200 \mu \mathrm{mol} \mathrm{m} \mathrm{m}^{-2} \mathrm{~s}^{-1}$, L20 is $20 \mu \mathrm{mol} \mathrm{m}$ $\mathrm{s}^{-1}$, L0 is $0 \mu \mathrm{mol} \mathrm{m} \mathrm{m}^{-2} \mathrm{~s}^{-1}$. In all, 10, 200 seeds were used: $80-100$ seeds with three repeats for phytohormone analysis and 50 seeds with five repeats for seed germination test at each temperature change (every 50 days). (The other $80-100$ seeds with three repeats were collected at each temperature for later proteome analysis as part of a different study) 
through a $0.22 \mu \mathrm{m}$ filter and transferred to $2 \mathrm{~mL}$ LC-MS bottles for UPLC-MS/MS analysis.

\section{Germination indices}

The seed germination process was using germination percentage $\left(G_{\mathrm{P}}\right)$, mean germination time $\left(T_{\mathrm{M}}\right)$ and germination value $\left(G_{\mathrm{V}}\right)$ calculated as follows:

$G_{\mathrm{P}}=n / N_{\mathrm{t}}$

where, $n$ is the number of germinated seeds and $N_{\mathrm{t}}$ is the total number of tested seeds.

$T_{\mathrm{M}}=\sum\left(n_{d} d\right) / N_{\mathrm{g}}$

where, $n_{d}$ is the number of germinated seeds on a given day $d, d$ is the number of days after the start of the experiment, and $N_{\mathrm{g}}$ is the total number of seeds germinated (Daws et al. 2002; Xia et al. 2016).

$$
\begin{gathered}
G_{\mathrm{MD}}=\frac{G_{\mathrm{P}}}{d} \\
P_{\mathrm{v}}=\frac{\sum G_{\mathrm{p}}}{d} \\
G_{\mathrm{v}}=P_{\mathrm{v}} G_{\mathrm{MD}}
\end{gathered}
$$

where, $G_{\mathrm{MD}}$ is mean daily germination. The peak day is the day when the most seeds had germinated. $\Sigma G_{\mathrm{P}}$ is the cumulative germination percentage, $P_{\mathrm{V}}$ is the peak value, which is represented as the daily mean germination percentage from the beginning of the test to the peak day (Reum et al. 2018).

\section{Data analyses}

The data sets were tested for normality by using normal probability plots. Arcsine-square-root or log transformation was applied to meet the assumptions of ANOVA (Seiwa et al. 2009). Two-way ANOVA was adopted to test for differences in $G_{\mathrm{P}}, T_{\mathrm{M}}, G_{\mathrm{V}}$ and phytohormones in embryos and endosperms of seeds after storage in different light and temperature conditions. Differences at $P \leq 0.05$ were considered significant. SPSS 23.0 (IBM, Armonk, NY, USA) was used for all calucaltions and analyses. Graphs were generated by SigmaPlot 14.0 (SYSTAT, Chicago, IL, USA).

\section{Results}

\section{$\mathrm{GA}_{3}, \mathrm{ABA}$ levels in seeds in response to storage light and temperature conditions}

Light and temperature each had a significant effect on $\mathrm{GA}_{3}$ and $\mathrm{ABA}$ concentrations and the ratio of GA/ABA in the embryo and endosperm, except for temperature, which had no significant effect on $\mathrm{GA}_{3}$ in the endosperm (Table 1). The
Table 1 Two-way ANOVA of phytohormones in embryo and endosperm of Pinus koraiensis

\begin{tabular}{|c|c|c|c|c|c|c|}
\hline Seed part & Hormone & Source & SS & $d f$ & $F$ & $P$ \\
\hline \multirow[t]{9}{*}{ Embryo } & \multirow[t]{3}{*}{$\mathrm{GA}_{3}$} & Temp & 5.68 & 3,42 & 30.31 & $\mathbf{0 . 0 0}$ \\
\hline & & Light & 4.94 & 2,42 & 39.53 & 0.00 \\
\hline & & Temp $\times$ Light & 4.33 & 6,42 & 11.56 & 0.00 \\
\hline & \multirow[t]{3}{*}{ ABA } & Temp & 4.33 & 3,43 & 23.93 & 0.00 \\
\hline & & Light & 19.90 & 2,43 & 164.87 & 0.00 \\
\hline & & Temp $\times$ Light & 1.15 & 6,43 & 3.17 & 0.01 \\
\hline & \multirow[t]{3}{*}{ GA/ABA } & Temp & 1.52 & 3,42 & 7.98 & 0.00 \\
\hline & & Light & 42.84 & 2,42 & 338.03 & 0.00 \\
\hline & & Temp $\times$ Light & 1.76 & 6,42 & 4.62 & 0.00 \\
\hline \multirow[t]{9}{*}{ Endosperm } & \multirow[t]{3}{*}{$\mathrm{GA}_{3}$} & Temp & 0.25 & 3,40 & 1.67 & 0.19 \\
\hline & & Light & 1.11 & 2,40 & 11.19 & 0.00 \\
\hline & & Temp $\times$ Light & 0.81 & 6,40 & 2.72 & 0.03 \\
\hline & \multirow[t]{3}{*}{ ABA } & Temp & 2.67 & 3,43 & 25.60 & 0.00 \\
\hline & & Light & 19.75 & 2,43 & 284.50 & 0.00 \\
\hline & & Temp $\times$ Light & 0.21 & 6,43 & 1.02 & 0.42 \\
\hline & \multirow[t]{3}{*}{ GA/ABA } & Temp & 1.28 & 3,40 & 6.66 & 0.00 \\
\hline & & Light & 28.79 & 2,40 & 224.95 & 0.00 \\
\hline & & Temp $\times$ Light & 0.67 & 6,40 & 1.73 & 0.14 \\
\hline
\end{tabular}
seeds after storage in different light and temperature regimes
$\mathrm{SS}$ is sum of squares. GA, ABA, GA/ABA values weremultiplied by $10^{4}$ and log-transformed before analysis to meet normal distribution. Significant $P$ values are in bold 
interaction effect of light and temperature was also significant for $\mathrm{GA}_{3}$ concentration in the embryo and endosperm and for $A B A$ and $G A / A B A$ in the embryo but not for $A B A$ or GA/ABA in endosperm (Table 1). $\mathrm{GA}_{3}$ concentrations in the embryo in L0 and in the endosperm in L200 decreased with temperatures from T-5 to T25 (Fig. 2). From T25 to $\mathrm{T} 15, \mathrm{GA}_{3}$ concentrations in the embryo and endosperm in all the three light levels stayed almost the same. In L20, $\mathrm{GA}_{3}$ concentrations in the embryo and endosperm of seeds varied insignificantly with the temperature levels. At T-5, the $\mathrm{GA}_{3}$ concentration in L200 was significantly higher than in L20 and L0 in the endosperm, but in L200 and L20 was significantly lower than in L0 in the embryo. However, at $\mathrm{T} 25$ and $\mathrm{T} 15$, no significant differences were found for $\mathrm{GA}_{3}$ concentrations in the embryo and endosperm among all the three light conditions (Fig. 2). The ABA concentrations in the embryo and endosperm had a similar trend in response to the temperature levels; they decreased from T-5 to T25 and increased as the temperature decreased from $\mathrm{T} 25$ to $\mathrm{T} 15$
(Fig. 2). In all light treatments, the ABA concentrations in the embryo and endosperm were the lowest at T25 (Fig. 2). The ABA concentrations in L20 were significantly higher than in L200 and L0 for all temperatures (Fig. 2).

In the embryo, GA/ABA decreased as temperature increased (in the order T-5, T5, T25, T15) in L200 and L0, but in L20 increased as the temperature increased from T-5 to T25 and decreased from T25 to T15. In the endosperm, GA/ABA increased from T-5 to T25 and decreased from T25 to T15 in all three light levels (Fig. 2).

\section{Germination of $P$. koraiensis seeds in response to light and storage temperature}

$G_{\mathrm{P}}, T_{\mathrm{M}}$ and $G_{\mathrm{V}}$ for seeds were significantly affected by light, temperature and their interaction (Table 2). At T-5, T5 and $\mathrm{T} 25, G_{\mathrm{P}}$ in L200 and L20 was significantly higher than in the dark (Fig. 3). At T15, $G_{\mathrm{P}}$ did not differ significantly among L200, L20 and L0. Moreover, $G_{\mathrm{P}}$ for T-5/ L200 was below
Fig. $2 \mathrm{GA}_{3}, \mathrm{ABA}$ and $\mathrm{GA} /$ ABA in the embryo and endosperm of imbibed seeds of Pinus koraiensis seeds in different light levels and temperatures. L200 is $200 \mu \mathrm{mol}$ $\mathrm{m}^{-2} \mathrm{~s}^{-1}, \mathrm{~L} 20$ is $20 \mu \mathrm{mol} \mathrm{m} \mathrm{m}^{-2}$ $\mathrm{s}^{-1}$, L0 is $0 \mu \mathrm{mol} \mathrm{m} \mathrm{m}^{-2} \mathrm{~s}^{-1}$; T-5: $-5{ }^{\circ} \mathrm{C}$ (50 days), $\mathrm{T} 5:-5^{\circ} \mathrm{C}$ (50 days) $+5{ }^{\circ} \mathrm{C}$ (50 days), T25: $-5^{\circ} \mathrm{C}$ (50 days) $+5{ }^{\circ} \mathrm{C}$ (50 days $)+25^{\circ} \mathrm{C}(50$ days $)$, $\mathrm{T} 15:-5^{\circ} \mathrm{C}(50$ days $)+5^{\circ} \mathrm{C}$ (50 days) $+25^{\circ} \mathrm{C}$

(50 days) $+15^{\circ} \mathrm{C}$ (50 days). Different capital letters indicate a significant difference in phytohormone concentrations among different light levels at the same temperature. Different small letters indicate a significant difference in phytohormone concentrations among different temperatures in the same light
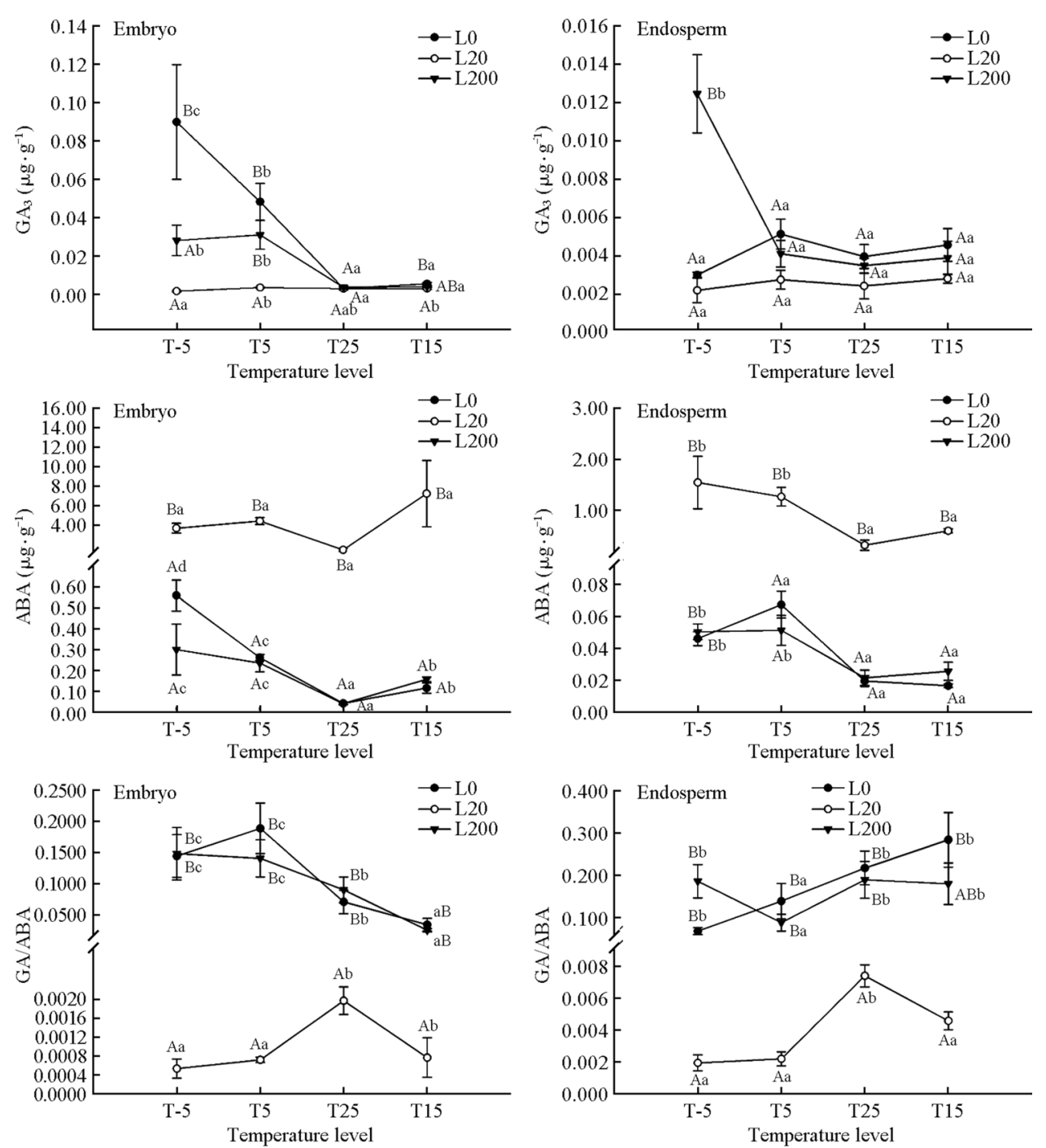
Table 2 Two-way ANOVA of germination percentage $\left(G_{\mathrm{P}}\right)$, mean germination time $\left(T_{\mathrm{M}}\right)$ and germination value $\left(G_{\mathrm{V}}\right)$ of Pinus koraiensis seeds after storage in different light and temperature regimes

\begin{tabular}{|c|c|c|c|c|c|c|c|c|c|}
\hline \multirow[t]{2}{*}{ Source } & \multicolumn{3}{|l|}{$G_{\mathrm{P}}$} & \multicolumn{3}{|l|}{$T_{\mathrm{M}}$} & \multicolumn{3}{|l|}{$G_{\mathrm{V}}$} \\
\hline & $d f$ & $F$ & $P$ & $d f$ & $F$ & $P$ & $d f$ & $F$ & $P$ \\
\hline Light & 2,45 & 16.58 & 0.00 & 2,47 & 38.43 & 0.00 & 2,48 & 7.86 & 0.00 \\
\hline Temperature & 3,45 & 89.13 & 0.00 & 3,47 & 190.96 & 0.00 & 3,48 & 77.79 & 0.00 \\
\hline Light $\times$ Temperature & 6,45 & 6.28 & 0.00 & 6,47 & 64.74 & 0.00 & 6,48 & 2.93 & 0.02 \\
\hline
\end{tabular}

Significant $P$ values are in bold

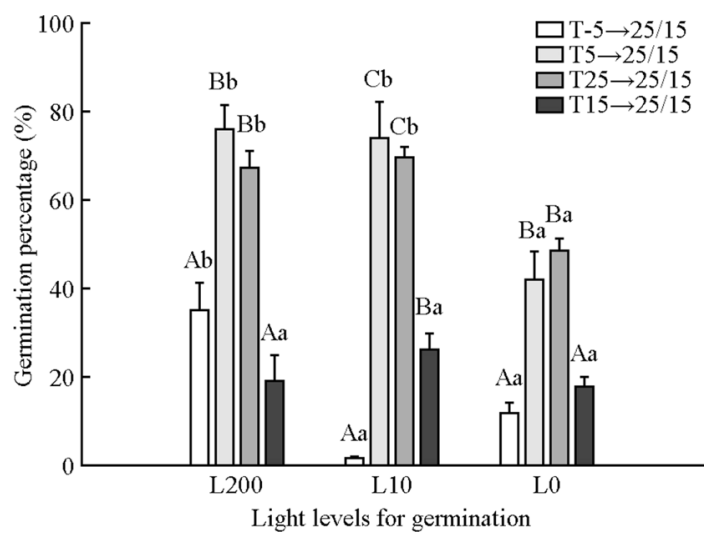

Fig. 3 Germination percentage $\left(G_{\mathrm{P}}\right)$ of Pinus koraiensis seeds in different light and temperature regimes. L200 is $200 \mu \mathrm{mol} \mathrm{m} \mathrm{m}^{-2} \mathrm{~s}^{-1}$, $\mathrm{L} 20$ is $20 \mu \mathrm{mol} \mathrm{m}{ }^{-2} \mathrm{~s}^{-1}$, L0 is $0 \mu \mathrm{mol} \mathrm{m}{ }^{-2} \mathrm{~s}^{-1}$; $\mathrm{T}-5:-5{ }^{\circ} \mathrm{C}$ (50 days), T5: $-5{ }^{\circ} \mathrm{C}$ (50 days $)+5{ }^{\circ} \mathrm{C}(50$ days $), \mathrm{T} 25:-5{ }^{\circ} \mathrm{C}(50$ days $)+5{ }^{\circ} \mathrm{C}$ (50 days) $+25{ }^{\circ} \mathrm{C} \quad(50$ days $), \quad \mathrm{T} 15:-5{ }^{\circ} \mathrm{C} \quad(50$ days $)+5{ }^{\circ} \mathrm{C}$ (50 days) $+25^{\circ} \mathrm{C}(50$ days $)+15{ }^{\circ} \mathrm{C}(50$ days $)$. Different capital letters indicate a significant difference in $G_{\mathrm{P}}$ among different temperatures in the same light. Different small letters indicate a significant difference in $G_{\mathrm{P}}$ among different light levels at the same temperature
$40 \%$ and below $10 \%$, for T-5 / L20. To summarize, the positive effect of light on dormancy release and germination of $P$. koraiensis seeds apparently relies on optimum temperatures at $\mathrm{T} 5$ and $\mathrm{T} 25$.

In all light conditions, $G_{\mathrm{P}}$ for seeds stored at T5 and T25 was significantly higher than at T-5 and T15 (Fig. 3), indicating that the optimum temperature for germination of the seeds was $\mathrm{T} 5$ and $\mathrm{T} 25$.

$T_{\mathrm{M}}$ was the longest in L200/T-5 and L0/T-5 and the shortest in L200/T15 and L0/T15 (Fig. 4). In L20, $T_{\mathrm{M}}$ at T5 and $\mathrm{T} 15$ was significantly longer than at T-5 and T25. In all light levels, $T_{\mathrm{M}}$ was longer at $\mathrm{T} 5$ than at $\mathrm{T} 25$. At $\mathrm{T} 5, T_{\mathrm{M}}$ was significantly higher in L0 than in the other light levels.

The effect of light and temperature on $G_{\mathrm{V}}$ was similar to that on $G_{\mathrm{P}}$ (Fig. 4). At T5 and T25, $G_{\mathrm{V}}$ was significantly higher in L200 and L20 than in L0. No significant differences were found among all three light levels at T-5 and T15 (Fig. 4). For all three light levels, $G_{\mathrm{V}}$ was significantly higher at T25 than at T-5, T5 and T15 (Fig. 4).

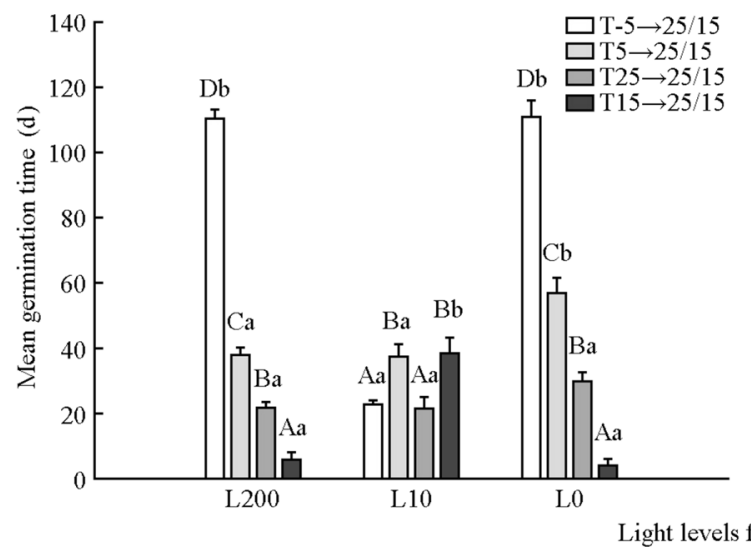

Fig. 4 Mean germination time $\left(T_{\mathrm{M}}\right)$ and germination value $\left(G_{\mathrm{V}}\right)$ of Pinus koraiensis seeds in different light and temperature regimes. $\mathrm{L} 200$ is $200 \mu \mathrm{mol} \mathrm{m}{ }^{-2} \mathrm{~s}^{-1}$, L20 is $20 \mu \mathrm{mol} \mathrm{m}^{-2} \mathrm{~s}^{-1}$, L0 is $0 \mu \mathrm{mol} \mathrm{m}{ }^{-2}$ $\mathrm{s}^{-1}$; T-5 $\rightarrow 25 / 15$, T5 $\rightarrow 25 / 15$, T25 $\rightarrow 25 / 15$ and T15 $\rightarrow 25 / 15$ represent germination test at $25{ }^{\circ} \mathrm{C} / 15^{\circ} \mathrm{C}$ after storage at T-5, T5, T25 and

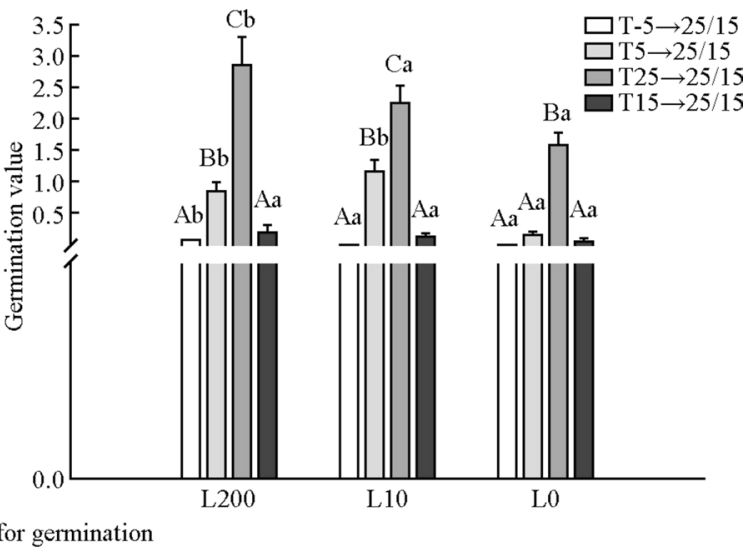

T15, respectively. Different capital letters indicate a significant difference in $T_{\mathrm{M}}\left(G_{\mathrm{V}}\right)$ among different temperatures in the same light. Different small letters indicate a significant difference in $T_{\mathrm{M}}\left(G_{\mathrm{V}}\right)$ among different light levels at the same temperature 


\section{Correlation between GA, ABA, GA/ABA and germination}

With respect to the relationship between the phytohormones and $G_{\mathrm{V}}$ of seeds, significantly negative correlations were found between ABA concentrations in the embryo and $G_{\mathrm{V}}$ for both L20 and L200 (Fig. 5). In addition, the GA/ABA in embryo was significantly positively correlated with $G_{\mathrm{V}}$ for L20 (Fig. 5). However, no observable correlations between $G_{\mathrm{V}}$ and $\mathrm{GA}_{3}$ or ABA concentrations in either the embryo or endosperm were found for L0 (Fig. 5).

\section{Discussion}

Temperature has been known to regulate both dormancy and germination (Bewley and Black 1994; Pons 2000; Baskin and Baskin 2004; Fenner and Thompson 2005), but whether light is also a regulator of dormancy has been under debate. In the present study, without light irradiance (L0 light treatment), the $G_{\mathrm{P}}$ reached $40-60 \%$ after a specific period of stratification at suitable temperatures (T5, T25) (Fig. 3) but was less than 40\% in L200 and less than 10\% in L20, at T-5. Song and Zhu (2016) adopted the $G_{\mathrm{P}}$ threshold to define the dormancy and dormancy release of $P$. koraiensis seeds; seeds were dormant if the $G_{\mathrm{P}}$ was below $10 \%$ and completely released from dormancy when the $G_{\mathrm{P}}$ was higher than $80 \%$. According to this criterion, we concluded that light was not the necessary factor for dormancy release of $P$. koraiensis seeds and that the role of temperature on dormancy release was far more important than light. We also confirmed that the light and temperature treatments need to be carried out in a set order for them to be effective at releasing dormancy; that is, light must come last to be effective (Finch-Savage and Leubner-Metzger 2006). In addition, temperature was demonstrated to work over time to alter the depth of dormancy, whereas light was an immediate way to make conditions suitable for germination. As the storage temperature changed in the order T-5, T5, T25, T15, $G_{\mathrm{P}}$ and $G_{\mathrm{V}}$ increased first, then decreased in all light levels (Figs. 3, 4), whereas the ABA concentrations changed in the opposite directions (Fig. 2). These results demonstrated that the dormancy of $P$. koraiensis seeds was released when the storage temperature increased from T-5 to T25 but was initiated again when the temperature decreased from $\mathrm{T} 25$ to T15 through the whole stratification period.

Light and temperature regulate seed germination for many species (Pons 2000; Baskin and Baskin 2004; Fenner and Thompson 2005). For P. koraiensis seeds, in all light levels, the $G_{\mathrm{P}}$ and $G_{\mathrm{V}}$ were higher at T5 and T25 than at T-5 and T15 (Figs. 3, 4), demonstrating the critical role of temperature on germination. Thus, we considered T5 and T25 as the optimum temperature conditions for primary dormancy release. Low temperatures $\left(0\right.$ to $\left.5^{\circ} \mathrm{C}\right)$ have been known to
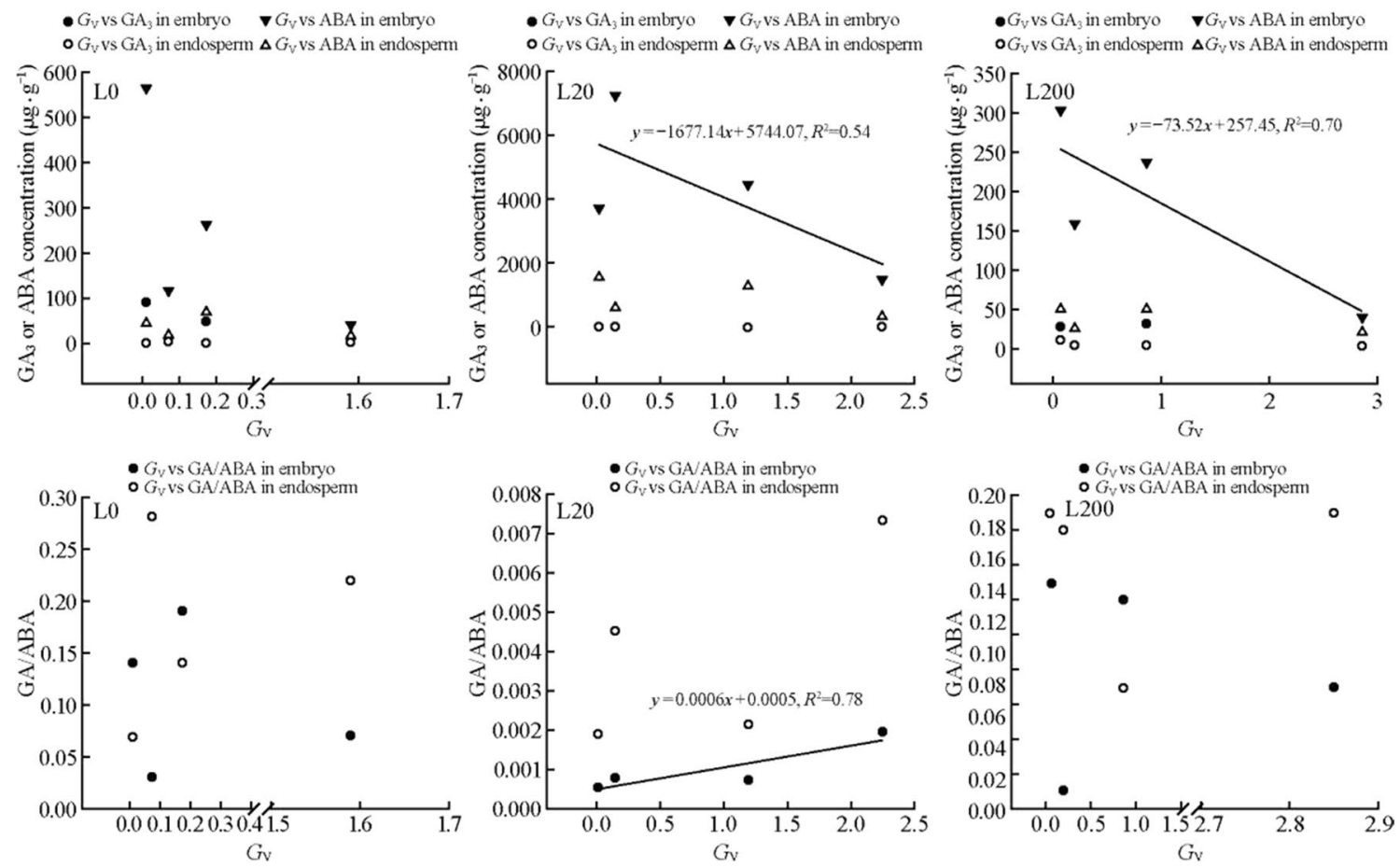

Fig. 5 Correlations between germination value $\left(G_{\mathrm{V}}\right)$ and GA or ABA concentrations and GA/ABA in the embryo and endosperm of $P$. koraiensis seeds. L200 is $200 \mu \mathrm{mol} \mathrm{m}{ }^{-2} \mathrm{~s}^{-1}$, L20 is $20 \mu \mathrm{mol} \mathrm{m}{ }^{-2} \mathrm{~s}^{-1}$, L0 is $0 \mu \mathrm{mol} \mathrm{m}^{-2} \mathrm{~s}^{-1}$ 
be efficient for primary dormancy release of $P$. koraiensis seeds (Song and Zhu 2016), whereas high temperature delays dormancy release and induces secondary dormancy in several plant species (Larsen and Eriksen 2004; Brändel 2005; Song and Zhu 2016). However, we found that high temperature $\left(25^{\circ} \mathrm{C}\right)$ immediately after a low temperature $\left(5{ }^{\circ} \mathrm{C}\right)$ treatment also facilitated dormancy release by shortening the germination process (Fig. 4) and elevating the $G_{\mathrm{V}}$ (Fig. 4) of P. koraiensis seeds. These different results also suggest that the effect of temperature on dormancy induction is not only dependent on the prevailing temperature, but also on the temperature experienced by seeds during a previous dormancy release and the resulting dormancy status of the seed population (Malavert et al. 2017). Moreover, a gradual increase in the ambient temperature is required for the induction of secondary dormancy of two Carex species by high temperature (Brändel and Schütz 2003).

In addition, the $G_{\mathrm{P}}$ and $G_{\mathrm{V}}$ were higher in L200 and L20 than in the dark (L0) at optimum temperatures; thus, light irradiance facilitated germination of $P$. koraiensis seeds. The positive effect of light on seed germination of $P$. pinaster, $P$. sylvestris, $P$. koraiensis has also been confirmed previously (Ruano et al. 2009; Gaudio et al. 2011; Zhang et al. 2015). Flores et al. (2011) proposed that sensitivity to light during seed germination was a key strategy to prevent gemination when the place or time was unfavorable for seedling establishment. Because the effect of light on germination disappeared when the stratification temperature decreased from $25^{\circ} \mathrm{C}$ to $15^{\circ} \mathrm{C}$ (Figs. 3, 4), we speculate that light is not effective for germination after secondary dormancy is induced by a temperature decrease from 25 to $15^{\circ} \mathrm{C}$ and this might be a strategy for $P$. koraiensis to avoid germination during subsequently unfavorable seasons (such as winter).

GA stimulates seed germination, and ABA initializes seed dormancy (Bewley 1997; Chen et al. 2008; Miransari and Smith 2014; Deng et al. 2016; Guo et al. 2020). However, the variations in $\mathrm{GA}_{3}$ levels did not parallel the $G_{\mathrm{P}}$ or $G_{\mathrm{V}}$ patterns in response to light or temperature, which indicates that GA did not act as the stimulator for P. koraiensis germination in this study. Although $\mathrm{GA}_{3}$ and $\mathrm{ABA}$ contents were affected significantly by the stratification light and temperature levels (Table 1), no consistent trend was found between the $\mathrm{GA}_{3}$ or $\mathrm{ABA}$ concentrations and the final $G_{\mathrm{P}}$ in the three light levels with any temperature treatment. Thus, the phytohormone levels induced by the light treatments were not the cause of the dormancy release. The changes in the ABA concentrations in response to changes in storage temperatures were opposite the changes in $G_{\mathrm{P}}$ or $G_{\mathrm{V}}$, demonstrating that ABA levels contributed to the $G_{\mathrm{P}}$ results at different temperatures. A specific period of stratification at the optimum temperature (T5 and T25) might thus facilitate a change in the ABA concentration to further promoted dormancy release in P. koraiensis seeds. This result is in accordance with the finding that temperature conditions during the cold stratification period can affect the dormancy depth of $P$. koraiensis seeds (Song and Zhu 2016; Song et al. 2020b). Therefore, the impacts of light and temperature on seed germination are likely due to different pathways. Light regulation of seed germination has been reported to be controlled by GA or ABA biosynthesis through the action of phytochrome (Oh et al. 2006; Seo et al. 2009) and that temperature affects seed germination directly through GAs and ABA levels (Argyris et al. 2008; Song et al. 2020b) or the sensitivity to GA or ABA concentrations (Xia et al. 2019). The germination advantages in forest gaps with greater light transmittance are suggested to be due to greater temperature fluctuations (Pearson et al. 2002). Nevertheless, we found higher $G_{\mathrm{P}}$ and $G_{\mathrm{V}}$ in L200 and L20 than in the dark after storage at T5 and $\mathrm{T} 25$. This result further revealed that light can affect seed germination directly instead indirectly through an effect on temperature. Further research is needed to fully elucidate the metabolic pathways and molecular mechanisms involved in light regulation of seed germination.

In addition to our study, other studies have also shown that seed germination performances are regulated by the ratio of $\mathrm{ABA} / \mathrm{GA}$ rather than the absolute amounts of either GA or ABA (Bicalho et al. 2015; Liu and Zhang 2016). Interestingly, in light $\mathrm{L} 20$ and $\mathrm{L} 200, G_{\mathrm{V}}$ was negatively correlated with ABA concentrations in the embryo of $P$. koraiensis seeds. In L20, $G_{\mathrm{V}}$ was positively correlated with GA/ABA in the embryo of $P$. koraiensis seeds. However, germination was not significantly correlated with phytohormone levels in P. koraiensis seeds in the dark. These results indicated that attributes of seed germination that are controlled by the changes in the ABA concentrations or the GA/ $\mathrm{ABA}$ ratios, which are generated by temperature levels, are dependent on the light conditions. Light irradiance seems to enhance the response of $P$. koraiensis seeds to phytohormone levels caused by temperature variations. Thus, light and temperature are coupled in their effect on phytohormone levels to induce germination of $P$. koraiensis seeds.

\section{Conclusions}

Temperature affected the dormancy release, but light was not necessary for the primary dormancy release of Pinus koraiensis seeds. The dormancy release of $P$. koraiensis seeds was closely related to a decrease in ABA concentration, which varied with temperature levels. Both temperature and light influenced the germination of $P$. koraiensis seeds. At the optimum stratification temperature (T5 and T25), light irradiance accelerated germination. Germination was controlled by the decrease in $\mathrm{ABA}$ concentration or an increase in GA/ABA in embryo in L200 and L20. Light irradiance might enhance the response of seeds to 
phytohormone changes caused by temperature variation. The specific pathways involved in light regulation of the germination of $P$. koraiensis seeds through phytochromes by acting on phytohormone levels or the sensitivity to phytohormone concentration need further research.

Acknowledgements We thank Professor Shihong Luo and his research team from Shenyang Agricultural University for phytohormone analyses. Thanks are also due to Mr. Gang Xu at Liaoning Provincial College of Communications and Ms. Shuang Xu at the Institute of Applied Ecology, Chinese Academy of Sciences for their help with the germination experiment and sample preparation for the phytohormone analyses.

Open Access This article is licensed under a Creative Commons Attribution 4.0 International License, which permits use, sharing, adaptation, distribution and reproduction in any medium or format, as long as you give appropriate credit to the original author(s) and the source, provide a link to the Creative Commons licence, and indicate if changes were made. The images or other third party material in this article are included in the article's Creative Commons licence, unless indicated otherwise in a credit line to the material. If material is not included in the article's Creative Commons licence and your intended use is not permitted by statutory regulation or exceeds the permitted use, you will need to obtain permission directly from the copyright holder. To view a copy of this licence, visit http://creativecommons. org/licenses/by/4.0/.

\section{References}

Argyris J, Dahal P, Hayashi E, Still DW, Bradford KJ (2008) Genetic variation for lettuce seed thermoinhibition is associated with temperature-sensitive expression of abscisic acid, gibberellins and ethylene biosynthesis, metabolism and response genes. Plant Physiol 148:926-947

Barreto LC, Herken DMD, Silva BMR, Munné-Bosch S, Garcia QS (2020) ABA and GA(4) dynamic modulates secondary dormancy and germination in Syngonanthus verticillatus seeds. Planta 251:86

Baskin CC, Baskin JMJ (eds) (2014) Seeds: ecology, biogeography, and evolution of dormancy and germination. Academic Press, San Diego, p 666

Baskin JM, Baskin CC (2004) A classification system for seed dormancy. Seed Sci Res 14:1-16

Bewley JD (1997) Seed germination and dormancy. Plant Cell 9(7):1055-1066

Bewley JD, Black M (1994) Seeds-physiology of development and germination, 2nd edn. Plenum Press, New York, p 349

Bian FY, Su JR, Liu WD (2018) Dormancy release and germination of Taxus yunnanensis seeds during wet sand storage. Sci Rep 8:3205

Bicalho EM, Pintó-Marijuan, M, Morales M, Müller M, Munné-Bosch S, Garcia QS (2015) Control of macaw palm seed germination by the gibberellin/abscisic acid balance. Plant Biol 117(5):990-996

Brändel M (2005) The effect of stratification temperatures on the level of dormancy in primary and secondary dormant seeds of two Carex species. Plant Ecol 178(2):163-169

Brändel M, Schütz W (2003) Seasonal dormancy patterns and stratification requirements in seeds of Verbena officinaiis L. Basic Appl Ecol 4:329-337

Brunvatne JO (1998) Influence of light quality on the germination of Betula papyrifera seeds. Scand J For Res 13(3):324-330
Carón MM, De Frenne P, Verheyen K, Quinteros A, Ortega-Baes P (2020) Germination responses to light of four Neotropical forest tree species along an elevational gradient in the southern Central Andes. Ecol Res 35:550-558

Chen SY, Kuo SR, Chien CT (2008) Roles of gibberellins and abscisic acid in dormancy and germination of red bayberry (Myrica rubra) seeds. Tree Physiol 28(9):1431-1439

Chen SY, Chien CT, Baskin JM, Baskin CC (2009) Storage behavior and changes in concentrations of abscisic acid and gibberellins during dormancy break and germination in seeds of Phellodendron amurense var. wilconii (Rutaceae). Tree Physiol 30:275-284

Daws MI, Burslem DFRP, Crabtree M, Kirkman P, Mullins C, Dalling JW (2002) Differences in seed germination responses may promote coexistence of four sympatric Piper species. Funct Ecol $16: 258-267$

Deng ZJ, Hu XF, Ai XR (2016) Dormancy release of Cotinus coggygdria seeds under pre-cold moist stratification: an endogenous abscisic acid/gibberellic acid and comparative proteomic analysis. New For 47(1):105-118

Fenner M, Thompson K (2005) The ecology of seeds. Cambridge University Press, Cambridge, p 260

Finch-Savage WE, Leubner-Metzger G (2006) Seed dormancy and the control of germination. New Phytol 171:501-523

Flores J, Jurado E, Chapa-Vargas L, Ceroni-Stuva A, Dávila-Aranda P, Galíndez G, Gurvich D, León-Lobos P, Ordóñez C, Ortega-Baes P, Ramírez-Bullón N, Sandoval A, Seal CE, Ullian T, Pritchard HW (2011) Seeds photoplastism and its relationship with some plant traits in 136 cacti taxa. Environ Exp Bot 71:79-88

Gaudio N, Balandier P, Gwenaël P, Philippe E, Dumas Y, Jean F, Ginisty C (2011) Light-mediated influence of three understorey species (Calluna vulgaris, Pteridium aquilinum, Molinia caerulea) on the growth of Pinus sylvestris seedlings. Eur J For Res 130:77-89

Guo CC, Shen YB, Shi FH (2020) Effect of temperature, light, and storage time on the seed germination of Pinus bungeana Zucc. Ex Endl.: the role of seed-covering layers and abscisic acid changes. Forests 11(3):300

Hutchins HE, Hutchins SA, Liu BW (1996) The roles of birds and mammals in Korean pine (Pinus koraiensis) regeneration dynamics. Oecologia 107:120-130

Kojima M, Kamada-Nobusada T, Komatsu H, Takei K, Kuroha T, Mizutani M, Ashikari M, Ueguchi-Tanaka M, Matsuoka M, Suzuki K, Sakakibara H (2009) Highly sensitive and high-throughput analysis of plant hormones using MS-Probe modification and liquid chromatography-tandem mass spectrometry: An application for hormone profiling in Oryza sativa. Plant Cell Physiol 50(7):1201-1214

Larsen SU, Eriksen EN (2004) Delayed release of primary dormancy and induction of secondary dormancy in seeds of woody taxa caused by temperature alterations. In: Nursery Crops Development, Evaluation, Production and Use. Acta Horticulture 63:91-100

Liu YY, Zhang DK (2016) Effects of hormone balance on Korean Hackberry seed germination. Afr J Agric Res 11(29):2650-2657

Liu Y, Müller K, El-Kassaby YA, Kermode AR (2015) Changes in hormone flux and signaling in white spruce (Picea glauca) seeds during the transition from dormancy to germination in response to temperature cues. BMC Plant Biol 15:292

Ma JL (1997) The evolution of Korean pine forest. J Northeast For Univ 25(5):66-70 ((in Chinese with English Abstract))

Malavert C, Batla T, Benech-Arnold RL (2017) Temperature-dependant regulation of induction into secondary dormancy of Polygonum aviculae L. seeds: a quantitative analysis. Ecol Model 352(24):128-138

Miransari M, Smith DL (2014) Plant hormones and seed germination. Environ Exp Bot 99:110-121 
Oh E, Yamaguchi S, Kamiya Y, Bae G, Chung W, Choi G (2006) Light activates the degration of PIL5 protein to promote seed germination through gibberellin in Arabidopsis. Plant J 47:124-139

Pearson TRH, Burslem DFRP, Mullins CE (2002) Germination ecology of neotropical pioneers: interacting effects of environmental conditions and seed size. Ecology 83(10):2798-2807

Pipinis E, Stampoulidis A, Milios E, Kitikidou K, Akritidou S, Theodoridou S, Radoglou K (2020) Effects of seed moisture content, stratification and sowing date on the germination of Corylus avellana seeds. J For Res 31(3):743-749

Pons TL (2000) Seed responses to light. In: Fenner M (ed) Seeds-the ecology of regeneration in plant communities. CAB International, Wallingford, pp 237-260

Reum HA, Jung KH, Bin JJ, Sun PP (2018) Seed germination and initial seedling survival of the subalpine tree species, Picea jezoensis, on different forest floor substrates under elevated temperature. For Ecol Manag 429:579-588

Ruano I, Pando V, Bravo F (2009) How do light and water influence Pinus pinaster Ait. germination and early seedling development? For Ecol Manag 258:2647-2653

Seiwa K, Ando M, Imaji A, Tomita M, Kanou K (2009) Spatio-temporal variation of environmental signals inducing seed germination in temperate conifer plantations and natural hardwood forests in northern Japan. For Ecol Manag 257:361-369

Seo M, Nambara E, Choi G, Yamaguchi S (2009) Interaction of light and hormone signals in germinating seeds. Plant Mol Biol 69:463-472

Shu K, Liu XD, Xie Q, He ZH (2016) Two faces of one seed: hormonal regulation of dormancy and germination. Mol Plant 9:34-35

Song Y, Zhu JJ (2016) How does moist cold stratification under field conditions affect the dormancy release of Korean pine seed (Pinus koraiensis). Seed Sci Technol 44(1):27-42

Song Y, Zhu JJ, Yan QL, Wang GC (2018) Korean pine seed: linking changes in dormancy to germination in the 2 years following dispersal. Forestry 91(1):98-109

Song Y, Zhu JJ, Yan QL (2020a) Roles of abscisic acid and gibberellins in maintaining primary and secondary dormancy of Korean pine (Pinus koraiensis Sieb. et Zucc.) seeds. J For Res 31:2423-2434
Song Y, Zhu JJ, Yan QL (2020b) The temperature and length for the release of primary and induction of secondary physiological dormancy in Korean pine seeds. New For 51:657-669

Song Y (2016) On seed dormancy mechanisms of Korean pine (Pinus koraiensis Sieb. et Zucc.). Ph.D. thesis. Shenyang: Institute of Applied Ecology, Chinese Academy of Sciences, p 113

Thompson K (2000) The functional ecology of soil seed banks. In: Fenner M (ed) Seeds: the ecology of regeneration in plant communities. CAB International, Wallingford, pp 215-235

Vishal B, Kumar PP (2018) Regulation of seed germination and abiotic stresses by gibberellins and abscisic acid. Front Plant Sci 9:1-15

Vleeshouwers LM, Bouwmeester HJ, Karssen CM (1995) Redefining seed dormancy: an attempt to integrate physiology and ecology. J Ecol 83:1031-1037

Xia QQ, Ando M, Seiwa K (2016) Interaction of seed size with light quality and temperature regimes as germination cues in 10 temperate pioneer tree species. Funct Ecol 30:866-874

Xia Q, Ponnaiah M, Thanikathansubramanian K, Corbineau F, Bailly C (2019) Re-localization of hormone effectors is associated with dormancy alleviation by temperature and after-ripening in sunflower seeds open. Sci Rep 9(1):4861

Yan A, Chen Z (2020) The control of seed dormancy and germination by temperature, light and nitrate. Bot Rev 86:39-75

Zhang M, Yan QL, Zhu JJ (2015) Optimum light transmittance for seed germination and early seedling recruitment of Pinus koraiensis: implications for natural regeneration. iForest 8:e1-e7

Zhu JJ, Liu ZG, Wang HX, Yan QL, Fang HX, Hu LL, Yu LL (2008) Effects of site preparation on emergence and early establishment of Larix olgensis in montane regions of northeastern China. New For 36(3):247-280

Publisher's Note Springer Nature remains neutral with regard to jurisdictional claims in published maps and institutional affiliations. 